\title{
Flexure response of thermal loaded concrete specimens by acoustic emission method
}

\author{
Lubos Pazdera ${ }^{1, *}$, Libor Topolar ${ }^{1}$, Karel Mikulasek ${ }^{1}$, Jaroslav Smutny ${ }^{1}$, \\ Michaela Hodulakova ${ }^{1}$, Zdenek Chobola $^{1}$ and Herbert Seelman ${ }^{2}$ \\ ${ }^{1}$ Brno University of Technology, Faculty of Civil Engineering, Veveri 331/95 Brno, Czech Republic \\ ${ }^{2}$ Rail Data Services Austria GmbH \& Co KG, Steinergasse 11/5, A-1230 Wien, Austria
}

\begin{abstract}
The response to fire of concrete structural members depends on the thermal, mechanical, and deformation properties of concrete. These properties vary significantly with temperature depending on the composition and characteristics of the concrete batch mix as well as heating rate and other environmental conditions. The paper presents the effects of a high temperature on selected physical properties of concrete. The main aim of the article is the evaluation of monitoring concrete properties loaded in a few thermal steps up to $1200{ }^{\circ} \mathrm{C}$. Therefore, the concrete specimens were heated in a programmable laboratory furnace at a heating rate of $5{ }^{\circ} \mathrm{C} / \mathrm{min}$. The specimens were loaded at six temperatures, $200{ }^{\circ} \mathrm{C}, 400{ }^{\circ} \mathrm{C}, 600{ }^{\circ} \mathrm{C}, 800{ }^{\circ} \mathrm{C}, 1000{ }^{\circ} \mathrm{C}$, and $1200^{\circ} \mathrm{C}$ maintained for 60 minutes. The acoustic emission activity and some material characteristics were evaluated in a three-point bending test.
\end{abstract}

\section{Introduction}

Many cases of fires occurring in buildings, tunnels and other building structures stimulate interest in the behaviour of concrete at high temperatures. In a fire, the temperature may rise up to $1300{ }^{\circ} \mathrm{C}$, leading to damage in a concrete structure. [1]. Concrete is a poor heat conductor.

It is efficient to use acoustic emission technology to study crack damage location of concrete [2]. Non-destructive evaluation techniques are used to assess the condition of concrete structures, predict future performance, and monitor repair systems. One of the best-known non-destructive evaluation techniques is the acoustic emission method of detecting active defects in the tested materials [3]. Acoustic emission is a technique used widely for structural health monitoring purposes of several types of structures [4]. Piezoelectric sensors are mounted on the surface of the material or structure to record the motion of the surface under the elastic excitation of the cracking sources [5]. The rate and the characteristics of the received signals are strongly dependent on the damage process and enable the monitoring of fracture, corrosion and healing in cementitious materials [6]. There are two different ways to analyze cracks. Events are either described by acoustic emission parameters or analyzed, for example, by frequency spectra. Cracking in concrete

\footnotetext{
* Corresponding author: pazdera.1@,fce.vutbr.cz
} 
is a major problem in the design and durability of concrete structures. Various experimental methods have already been employed to detect the fracture process [7].

As a non-destructive method, acoustic emission can often be used to detect a failure at a very early stage of damage, long before a structure completely fails [8]. The article presents an experiment analysing the acoustic emission signals from the three-point bend testing of thermal loaded concrete specimens. Quantitative acoustic emission techniques were used to measure the micro fracture properties [9].

In engineering applications, active defects are a major hidden danger of structure security. The origin of micro-cracks in specimens is detected by using acoustic emission techniques with data samples collected, and, subsequently, the typical acoustic emission data acquired through experiment analyzed by using frequency spectra and other techniques. [10].

The frequency spectra of the recorded waveforms were obtained by Fast Fourier Transform [11]. The signals represented in the time domain can be investigated in other domains such as the frequency domain or the time-frequency domain. The Fourier transform clearly shows the natural frequency of the signals [12].

There are changes expected if concrete is heated up to [13]

$200{ }^{\circ} \mathrm{C} \quad$ slow capillary water loss and reduction in cohesive forces as water expand, ettringite dehydration, C-S-H gel dehydration, gypsum decomposition $\left(\mathrm{CaSO}_{4} 2 \mathrm{H}_{2} \mathrm{O}\right)$, physically bound water loss

$400{ }^{\circ} \mathrm{C} \quad$ break up of some siliceous aggregates (flint),

$600{ }^{\circ} \mathrm{C} \quad$ portlandite decomposition $\mathrm{Ca}(\mathrm{OH})_{2} \rightarrow \mathrm{CaO}+\mathrm{H} 2 \mathrm{O}$, quartz phase change $\beta-\alpha$ in aggregates and sands

$800{ }^{\circ} \mathrm{C} \quad$ second phase of the C-S-H decomposition, formation of $\beta-\mathrm{C}_{2} \mathrm{~S}$

$1000{ }^{\circ} \mathrm{C}$ dolomite decomposition calcite decomposition $\mathrm{CaCO}_{3} \rightarrow \mathrm{CaO}+\mathrm{CO}_{2}$, carbon dioxide release, ceramic binding initiation which replaces hydraulic bonds

$1200{ }^{\circ} \mathrm{C} \quad$ basalt melting

over $1200^{\circ} \mathrm{C}$ total decomposition of concrete, melting.

\section{Experimental set-up}

The three-point bending tests were performed on notched beams of cross section $100 \mathrm{~mm} \times$ $100 \mathrm{~mm}$ and length $400 \mathrm{~mm}$ (notch depth of $33 \mathrm{~mm}$ was placed in centre) as shown in Fig. 1. The beams were made from cement CEM I $42.5 \mathrm{R}$ of $345 \mathrm{~kg} / \mathrm{m}^{3}$, sand $0 / 4 \mathrm{of} 848 \mathrm{~kg} / \mathrm{m}^{3}$, coarse aggregate $8 / 16$ of $980 \mathrm{~kg} / \mathrm{m}^{3}$, water of $160 \mathrm{~kg} / \mathrm{m}^{3}$ and super-plasticizer of $3 \mathrm{~kg} / \mathrm{m}^{3}$. The specimens of common temperature were heated at a heating rate of $5{ }^{\circ} \mathrm{C} / \mathrm{min}$ up to a defined temperature maintained for 60 minutes and then placed in a room with a normal temperature. The defined temperatures were $200^{\circ} \mathrm{C}, 400{ }^{\circ} \mathrm{C}, 600^{\circ} \mathrm{C}, 800{ }^{\circ} \mathrm{C}, 1000^{\circ} \mathrm{C}$, and $1200^{\circ} \mathrm{C}$. The beams were loaded at a constant rate of extension until destruction [14]. In the sequel, the groups of specimens are marked by the corresponding temperatures, i.e. $200{ }^{\circ} \mathrm{C}$ is marked 200 and so on.

The fracture tests were carried out using a Heckert FPZ 100/1 testing machine within a range from 0 to $10 \mathrm{kN}$ at a laboratory of the Institute of Building Testing, Faculty of Civil Engineering, Brno University of Technology [15]. Two identical rigid metallic cylindrical supporting rollers and one loading ball were used for performing the three-point bending test. The distance of the supporting roller-specimen contact point from the centre of the beam was $300 \mathrm{~mm}$. The loading was applied to a ball at the top-middle zone of the specimen in order to achieve bending. A load-deflection diagram, which was used to calculate the elasticity modulus of the first part of the diagram, and of the effective fracture toughness, was recorded using an HBM SPIDER 8 device [16]. 
An acoustic emission measuring system XEDO made by DAKEL (Czech Republic) was used for the acoustic emission measurements. This system consisted of eight channels. The guard sensor eliminated mechanical and electrical noise. In this study, four acoustic type MIDI emission sensors (made by DAKEL) were used all having identical frequency ranges attached to the surface by beeswax [17]. Each sensor has a diameter of $6 \mathrm{~mm}$, height of 6.3 $\mathrm{mm}$ its advantage being small sensor \& exciter, compact full metal case, low noise, higher wear hardness and high frequency range. The sensors were placed around the expected location of the fracture process zone (Fig. 1).

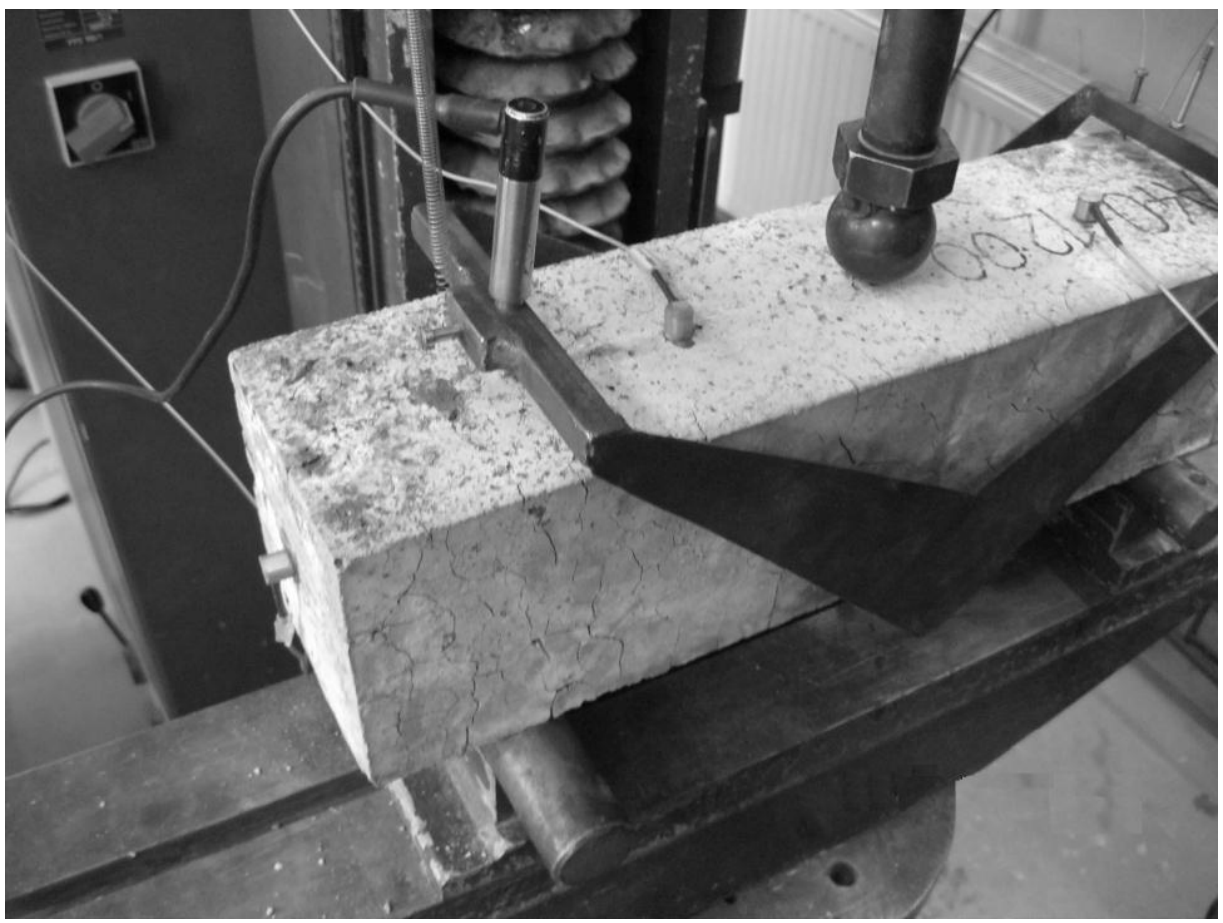

Fig. 1. Experimental set up.

A specimen was held in pressure and the acoustic emission sensors were placed in three different places as shown in Fig. 1. The acoustic emission measurement started after preloading the specimen. The "continuous" acoustic emission parameters such as acoustic emission energy, count etc. and some events were recorded. The signals (events) recorded were analyzed after finishing the experiment (off-line) by fast Fourier transform.

\section{Results}

Fig. 2 shows the shapes of stress and strength curves depending on the deformation and elongation respectively for each sample group. For the 20, 200, 400, and 600 sample groups, the curve shapes are similar showing a diminishing maximum strength with growing temperature. The shift of the maximum strength to higher elongations means a higher modulus of elasticity. For the remaining samples, that is, those exposed to temperatures higher that $600{ }^{\circ} \mathrm{C}$, the curve shapes are substantially different. Thus, from this temperature on, the changes of the concrete structure are very marked. 


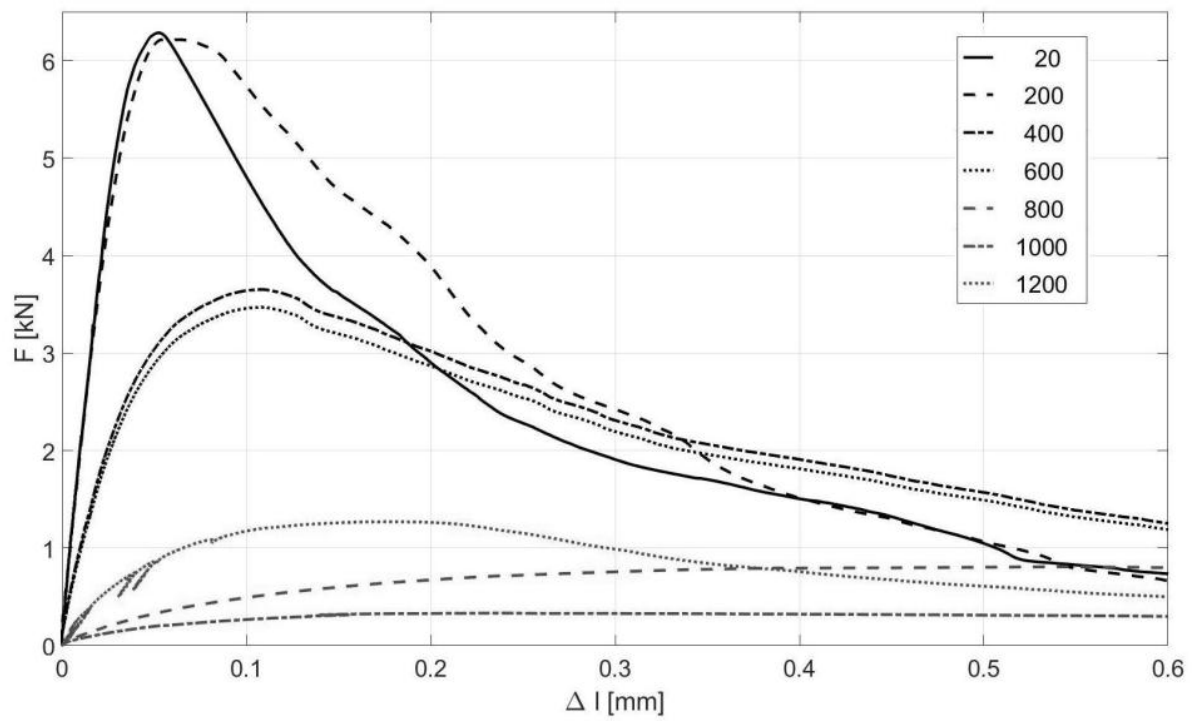

Fig. 2. The graph dependence of force on displacement of the three-point bending test of seven types of specimens.

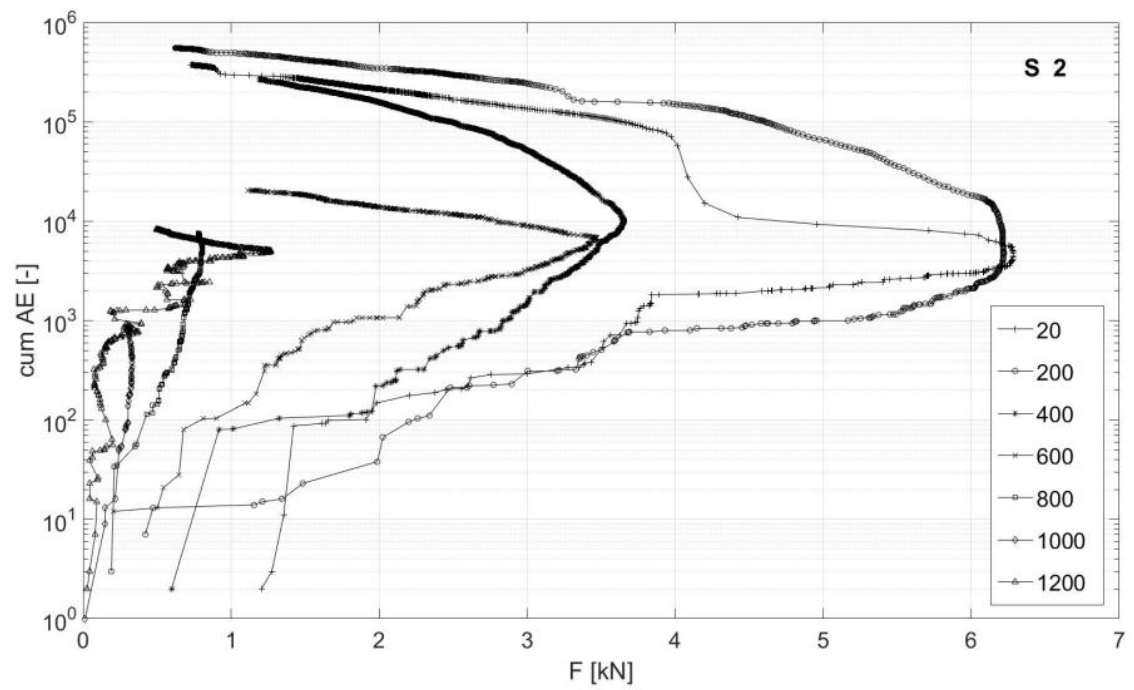

Fig. 3. The graph dependence of cumulative acoustic emission activity on loading of the three-point bending test of seven types of specimens degraded different temperature (in legend).

Fig. 3 shows the acoustic emission activity curve depending on the loading force for each sample group. In samples exposed to temperatures of up to $800{ }^{\circ} \mathrm{C}$, the acoustic emission activity curves are of a very similar nature. Samples 20 and 200 show the possibility of a standard use for building purposes, particularly, with the curve shapes being much the same with growing strength. As can be seen in Fig. 3, the acoustic emission activity sharply increases at approximately the half of the maximum strength. 

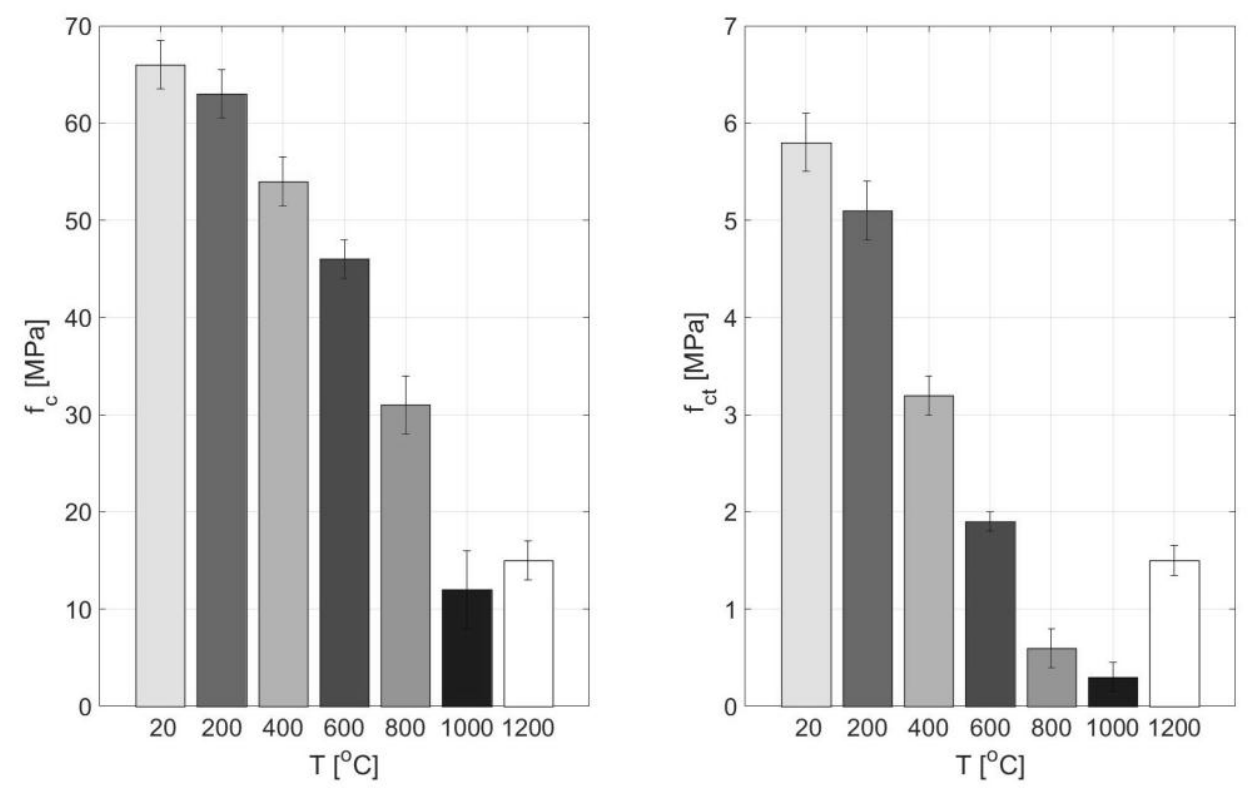

Fig. 4. Compressive strength $f_{c}$ and flexural bending strength $f_{c t}$ of specimens degraded different temperature $T$.

Fig. 4 shows the compressive strength and flexural bending strength depending on degradation temperature. The decreasing values of both strengths up to $1000{ }^{\circ} \mathrm{C}$ is obvious.
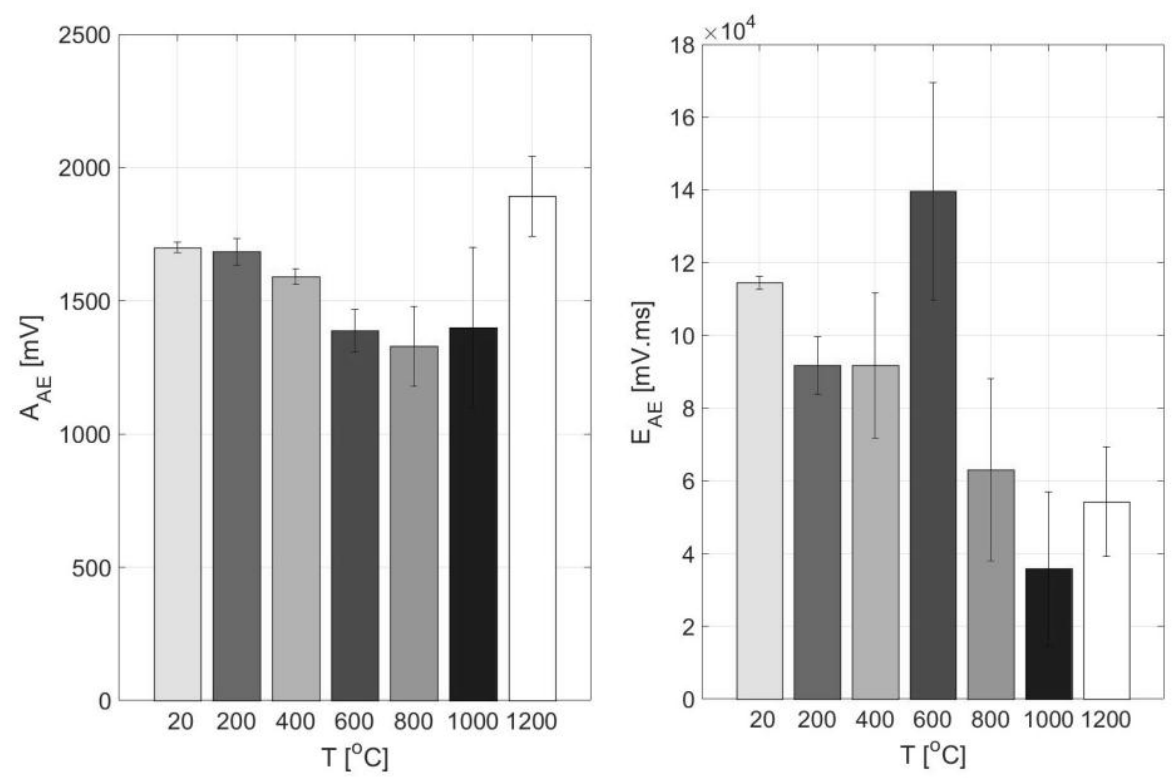

Fig. 5. Acoustic emission amplitude $A_{A E}$ (left) and acoustic emission energy $E_{A E}$ of specimens degraded different temperature $T$. 
Table 1. Acoustic emission events of temperature degraded specimens

\begin{tabular}{|c|c|c|c|c|c|c|c|}
\hline $\begin{array}{c}\text { Specimens } \\
\text { Degraded } \\
\text { temperature } \\
{\left[{ }^{\circ} \mathbf{C}\right]}\end{array}$ & 20 & 200 & 400 & 600 & 800 & 1000 & 1200 \\
\hline $\begin{array}{c}\text { Number of events } \\
\text { Average }\end{array}$ & 140 & 114 & 180 & 68 & 67 & 20 & 86 \\
\hline $\begin{array}{c}\text { Number of events } \\
\text { deviation }\end{array}$ & 5 & 6 & 15 & 4 & 7 & 6 & 5 \\
\hline
\end{tabular}

The evaluation of the acoustic emission activities of the monitored specimens being rather sophisticated, the graph as shown in Figure 3 can actually only be correctly interpreted by acoustic emission experts with long previous experience. This is the reason why the graphs in Figure 5 have been created for clearer presentation. The average acoustic emission amplitude is decreasing for specimens degraded in the temperature range of $600{ }^{\circ} \mathrm{C}$ to $1000{ }^{\circ} \mathrm{C}$, but higher at a degraded temperature of $1200{ }^{\circ} \mathrm{C}$. The material changes are different from a temperature of $800{ }^{\circ} \mathrm{C}$. Acoustic emission energy in Fig. 5 has a shape similar to the compressive strength and flexural bending strength in Fig. 4. A similar result of the number of acoustic emission events is in Table 1, where the progress is similar to the common parameters in Fig. 4.

\section{Conclusion}

The acoustic emission method provides a detailed description of the behaviour of a sample under load. Monitoring its activity with as the loading strength grows makes it possible to determine by Figure 3 the limit amount of the acoustic emission energy released after which structure deformations can be expected $-1000{ }^{\circ} \mathrm{C}$ in our case. Its great advantage is that the amount of the energy released can be determined during the loading.

The behaviour of a sample in a loading temperature over $600{ }^{\circ} \mathrm{C}$ is already very difficult to follow, as the sample structure is no longer compact. Note that the samples were measured at a temperature of $20^{\circ} \mathrm{C}$ being previously heated to the desired temperature and then cooled down as described earlier.

The experiment describes the sample state under an extreme load such as a fire. After subsequent measurements, the behaviour of new mixes under an extreme temperature load can be defined in terms of the internal energy of the structure, which can be detected by the acoustic emission method very well. The data acquired can be employed to advantage in mathematical models to describe the behaviour of structures.

This paper has been written under the project GAČR No.16-02261S supported by Czech Science Foundation and the project No. LO1408 "AdMaS UP - Advanced Materials, Structures and Technologies", supported by Ministry of Education, Youth and Sports under the „National Sustainability Programme I" and under the projects No. FAST-S-16-2967 and No. FAST-J-17-4554 and No. FAST-S-16-2967 both supported by the Brno University of Technology.

\section{References}

1. X.H. Wang, J.J. Xiang, H.W. Hu, W. Xie, X.B. Li, Ultrasonics, 60 (2015)

2. K. Ohno, K. Uji, A. Ueno, M. Ohtsu, Construction and Building Materials, 67, SI (2014) 
3. Y. Jiang, C.H. Lee, J.P. Wu, Insight, 54, 3 (2012)

4. Y. Xu, D. Xu, J. Qu, X. Cheng, H. Jiao, S. Huang, Advances in Acoustic Emission Technology Springer Proceedings in Physics, 158 (2015)

5. Ch. Stergiopoulos, I. Stavrakas, D. Triantis, F. Vallianatos, J. Stonham, Physica A: Statistical Mechanics and its Applications, 419 (2015)

6. S. Muralidhara, B.K.R. Prasad, H. Eskandari, B.L. Karihaloo, Constr Build Mater, 24, 4 (2010)

7. J. Blom, M. El Kadi, J. Wastiels, D.G. Aggelis, Construction and Building Materials, 70 (2014)

8. J. Smutny, L. Pazdera, Insight, 46, 10 (2004)

9. L. Topolar, L. Pazdera, P. Cikrle, Applied Mechanics and Materials, 486 (2014)

10. L. Pazdera, L. Topolar, Russian Journal of Nondestructive Testing, 50, 2 (2014)

11. J. Smutny, DT \& E International, 37, 2 (2004)

12. F. Sha, D.Y. Xu, S.F. Huang, X. Cheng, Applied Mechanics and Materials (2013),

13. J. Piasta, Materials and Structures, 17, 6 (1989)

14. H. Simonova, I. Havlikova, P. Danek, Z. Kersner, T. Vymazal, Materiali in Tehnologije, 49, 3 (2015)

15. T. Vymazal, N. Zizkova, P. Misak, Ceramics-Silikaty, 53, 3 (2009)

16. I. Plskova, Z. Chobola, M. Matysik, Ceramics-Silikaty, 55, 2 (2011)

17. B. Kucharczykova, P. Misak, T. Vymazal, Russian Journal of Nondestructive Testing, 46, 3 (2010) 